\title{
Role of Macrophage Inflammatory Protein-3 $\alpha$ and Its Ligand CCR6 in Rheumatoid Arthritis
}

\author{
Jeffrey H. Ruth, Shiva Shahrara, Christy C. Park, Jacques C. M. Morel, \\ Pawan Kumar, Shixin Qin, and Alisa E. Koch
}

Department of Medicine (JHR, SS, CCP, JCMM, PK, AEK) Northwestern University Medical School, and Veteran's Administration Chicago Health Care System (AEK), Lakeside Division, Chicago, Illinois; and Millennium Pharmaceuticals (SQ), Cambridge, Massachusetts

\begin{abstract}
SUMMARY: We examined the expression and participation of CCR6 and its ligand MIP-3 $\alpha$ in rheumatoid arthritis (RA) by ELISA, RT-PCR, real-time PCR (TaqMan) analysis, monocyte chemotaxis, and two- and four-color flow cytometry. We found that RA synovial fluid (SF) contained significantly more MIP-3 $\alpha$ than osteoarthritis (OA), indicating a potential role for MIP-3 $\alpha$ in RA. IL-1 $\beta$, IL-18, and TNF- $\alpha$ stimulated RA fibroblast MIP-3 $\alpha$ production at 48 hours of incubation in vitro. By TaqMan analysis, there were more CCR6 mRNA transcripts in RA synovial tissue (ST) than in OA or normal (NL) ST, and elevated MIP-3 $\alpha$ mRNA expression in RA compared with NL ST. By FACS analysis, there were significantly elevated percentages of CD3+/CD4+/CD45RO+/ CCR6 + memory lymphocytes found in RA peripheral blood (PB) compared with NL PB or RA SF. We also found that MIP-3 $\alpha$ induced monocyte chemotactic activity at $1.25 \mathrm{pM}$, consistent with concentrations of MIP-3 $\alpha$ found in RA SF. Furthermore, MIP- $3 \alpha$ accounted for $40 \%$ of RA SF chemotactic activity for monocytes in modified Boyden chamber assays. We confirmed that MIP-3 $\alpha$ may be binding a G-coupled protein receptor because in vitro monocyte chemotaxis was inhibited by preincubation of monocytes with pertussis toxin. RA patient clinical data revealed that CD3+ lymphocyte/CCR6 expression inversely correlated with the age of the patient, indicating that CCR6 expression may be important in the development of RA at a younger age. Overall, these studies indicate that MIP-3 $\alpha$ and CCR6 may function to recruit monocytes and memory lymphocytes from the RA PB to the RA joint. These results further indicate that expression of CCR6, the receptor for MIP- $3 \alpha$, can be correlated with RA development. (Lab Invest 2003, 83:579-588).
\end{abstract}

$M$ IP-3 $\alpha$ is chemotactic not only for dendritic cells but also for CD45RO + (memory) T cells (Carramolino et al, 1999; Liao et al, 1999; Power et al, 1997; Schutyser et al, 2000). MIP-3 $\alpha$ is also a member of a large family of chemokines that attract leukocytes to the rheumatoid arthritis (RA) joint and also mediate angiogenesis (Szekanecz et al, 1998b). Furthermore, MIP-3 $\alpha$ binds the CCR6 receptor (Baba et al, 1997), the only known receptor for MIP- $3 \alpha$. Past investigations showed that MIP- $3 \alpha$ mediated dendritic cell traffic to lymph nodes for antigen processing and T-cell priming (Dieu et al, 1998). MIP-3 $\alpha$ has also been associated with a number of chronic inflammatory diseases, suggesting its participation in the inflammatory process. For instance, immunostaining for MIP-3 $\alpha$ was strongly augmented in lesional skin tissues from patients with atopic dermatitis compared

\section{DOI: 10.1097/01.LAB.0000062854.30195.52}

Received January 7, 2003.

This work was supported by National Institutes of Health Grants AI40987, HL58695, and CA79458-03. Additional support included the Gallagher Professorship for Arthritis Research and funds from the Veteran's Administration Research Service.

Address reprint requests to: Dr. Alisa E. Koch, Northwestern University Medical School, Department of Medicine, Section of Rheumatology, 303 East Chicago Avenue, Ward Building, 3-315, Chicago, IL 60611. E mail: ae-koch@northwestern.edu with normal tissue (Nakayama et al, 2001). MIP-3 $\alpha$ is found in human pancreatic cancer, where MIP-3 $\alpha$ and CCR6 mRNA transcripts were found in tumor cells. Moreover, abundant levels of MIP- $3 \alpha$ were found in tumor-associated macrophages (Kleeff et al, 1999). MIP- $3 \alpha$ has also been shown to arrest memory CD4+ $T$ cells by inducing integrin-dependent adhesion under physiologic flow conditions (Campbell et al, 1998). We hypothesized that MIP-3 $\alpha$ may play a role in RA pathogenesis.

We initially determined relative amounts of MIP-3 $\alpha$ in synovial fluid (SF) and found elevated concentrations of MIP-3 $\alpha$ in RA compared with osteoarthritis (OA). We next determined the expression and cellular source of MIP- $3 \alpha$ in RA by culturing ST fibroblasts and found that IL-1 $\beta$, IL-18, and TNF- $\alpha$ significantly stimulated synovial fibroblast MIP-3 $\alpha$ production. By fourcolor FACS analysis, we demonstrated that $\mathrm{CD} 3+1$ CD4+/CD45RO+/CCR6+ memory lymphocytes upregulated in $R A$ peripheral blood $(\mathrm{PB})$ compared with normal (NL) PB and RA synovial fluid (SF), suggesting that CCR6 may guide memory lymphocytes from the RA PB to the RA joint. Using TaqMan analysis, we found significantly higher amounts of CCR6 mRNA transcripts in RA synovial tissue (ST) than in OA or NL ST, likely as a result of CCR6+ memory lymphocyte ingress into the RA joint. We also found elevated amounts of MIP- $3 \alpha$ mRNA in RA ST compared with NL ST. 
It is interesting that a recent investigation revealed that human eosinophils express CCR6 and described eosinophil mRNA CCR6 transcripts by RT-PCR (Sullivan et al, 1999), suggesting that other cell types may express CCR6 and respond to MIP- $3 \alpha$. Therefore, we investigated the possibility that MIP- $3 \alpha$ may be chemotactic for monocytes, helping to explain, in part, the recruitment of monocytes into the RA joint. Using graded concentrations of $\mathrm{MIP}-3 \alpha$, we observed a significant increase in monocyte chemotactic activity at $1.25 \mathrm{pm} \mathrm{MIP-3 \alpha}$, consistent with the levels of MIP- $3 \alpha$ found in RA SF.

We assessed the contribution of RA SF MIP- $3 \alpha$ to in vitro monocyte chemotaxis by immunodepleting MIP-3 $\alpha$ with specific neutralizing antibody and showed an overall $40 \%$ inhibition of monocyte chemotaxis compared with sham-depleted RA SF. Furthermore, blocking monocyte $\mathrm{G}$ protein-coupled receptors with pertussis toxin (PTX) blocked MIP- $3 \alpha-$ mediated monocyte chemotaxis in vitro. Thus, we show that MIP-3 $\alpha$ is up-regulated in RA SF and likely participates in RA SF-mediated monocyte chemotaxis in vivo. We also show that CD3+/CD4+/CD45RO+/ CCR6+ lymphocytes are up-regulated in RA PB, indicating a role for CCR6 in memory lymphocyte homing from the RA PB to the RA joint. Taken together, these studies highlight important roles for MIP-3 $\alpha$ and CCR6 in monocyte- and memory lymphocyte-mediated inflammation in the RA joint.

\section{Results}

\section{MIP-3a Is Increased in RA SFs as Measured by ELISA}

RA and OA SFs were assayed for MIP-3 $\alpha$ by ELISA (Fig. 1). RA SFs exhibited significantly elevated levels of MIP-3 $\alpha(3001 \pm 800 \mathrm{pg} / \mathrm{ml}$; mean $\pm \mathrm{SE}, n=25)$ compared with SFs from patients with OA (100 \pm 100 $\mathrm{pg} / \mathrm{ml} ; n=9)$. This indicates that cells located within the ST and SF secrete MIP-3 $\alpha$ into the joint space.

\section{MIP-3 $\alpha$ Production in Conditioned Medium from RA ST

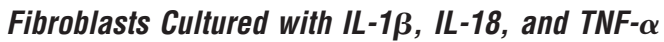

ST fibroblasts isolated from patients with RA were cultured in 24-well plates at 100,000 cells/ml for 48 hours. RA ST fibroblasts were grown in media containing IL-1 $\beta$ (30 ng/ml), IL-18 (90 ng/ml), TNF- $\alpha$ (30 $\mathrm{ng} / \mathrm{ml}$ ), or no cytokines (no stimulus), and the supernatants were assayed for MIP- $3 \alpha$ production by ELISA. As shown in Figure 2, IL-1 $\beta(1732 \pm 141 \mathrm{pg} / \mathrm{ml}$; $n=4)$, IL-18 (322 $\pm 42.4 \mathrm{pg} / \mathrm{ml} ; n=4)$, and TNF- $\alpha$ $(1438 \pm 292.1 \mathrm{pg} / \mathrm{ml} ; n=4$, mean $\pm \mathrm{SE})$ significantly enhanced fibroblast production of MIP- $3 \alpha$ compared with spontaneous fibroblast production (no stimulus, $122.5 \pm 61 \mathrm{pg} / \mathrm{ml} ; n=4)$ in vitro. This indicates that $\mathrm{IL}-1 \beta$, IL-18, and TNF- $\alpha$ may be primary inducers of MIP-3 $\alpha$ from ST fibroblasts in vivo.

\section{Expression of CCR6 on Human PB and SF CD3+ Lymphocytes by Flow Cytometry}

We found only a slightly detectable (barely above background levels) percentage of SF CD14+ monocytes expressing CCR6 in NL PB, RA PB, and RA SF (NL PB $0.0 \pm 0.0, n=8$; RA PB $2.8 \pm 0.7, n=21$; RA SF $3.0 \pm 0.6, n=25$ ) by flow cytometry, consistent with previous reports showing that monocytes do not express CCR6 (Fig. 3). We also measured CCR6 receptor expression on CD3+ lymphocytes but did not find differences in percentages of CCR6 expressing CD3+ lymphocytes from NL PB $(20.4 \pm 1.5, n=$ 8), RA PB (12.7 $\pm 3.6, n=22)$, and RA SF (17.4 \pm 2.4 , $n=18)$. By four-color flow cytometry, Figure 4 shows a significantly up-regulated population of $\mathrm{CD} 3+$ / CD4+/CD45RO+/CCR6+ memory lymphocytes

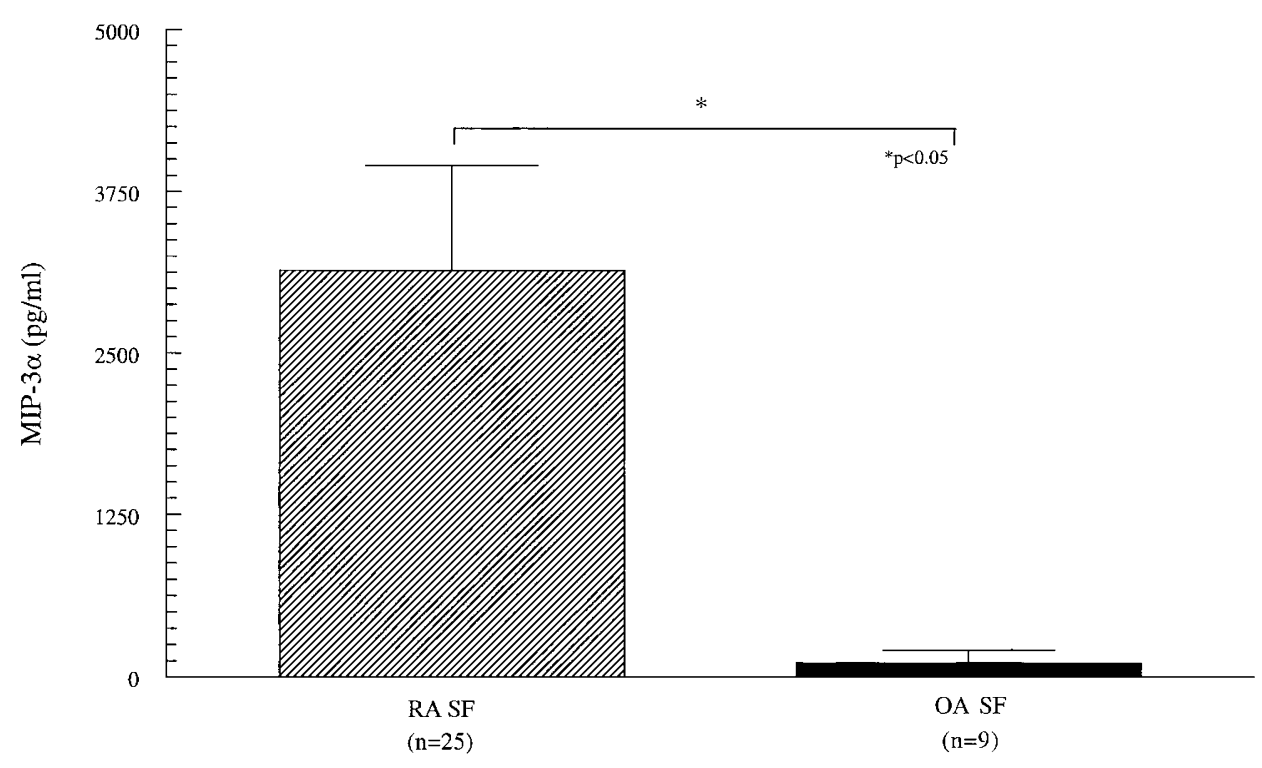

Figure 1.

Levels of MIP- $3 \alpha$ were measured by ELISA in RA SF and in OA SF. The MIP-3 $\alpha$ concentration was up-regulated in RA SF compared with OA SF. 


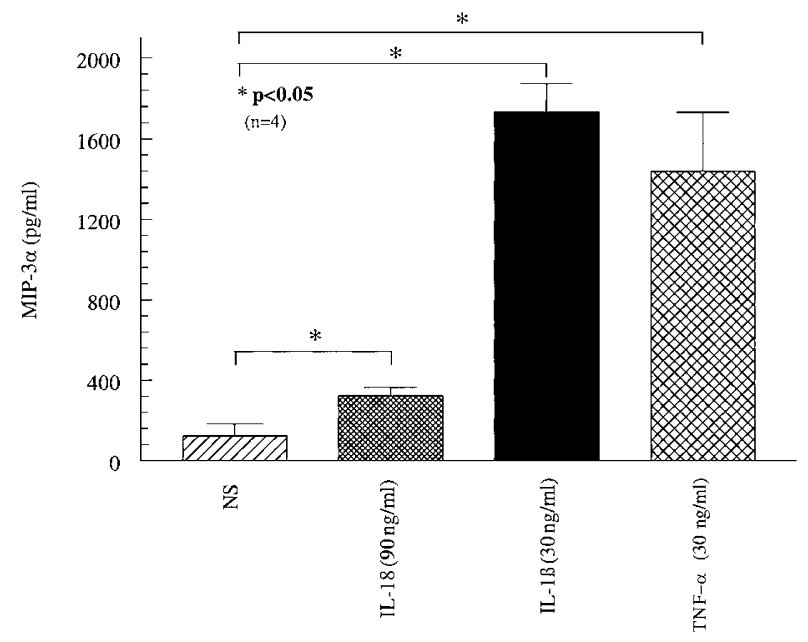

Figure 2.

To identify the cellular source of MIP-3 $\alpha$ in RA, we cultured RA synovial fibroblasts with no stimulus (NS), IL-18 (90 ng/ml), IL-1 $\beta$ (30 ng/ml), or TNF- $\alpha(30 \mathrm{ng} / \mathrm{ml})$ for 48 hours. Incubation of RA synovial fibroblasts with IL-1 $\beta$, IL-18, or TNF- $\alpha$ resulted in significant induction of MIP- $3 \alpha$ production from cultured RA fibroblasts.

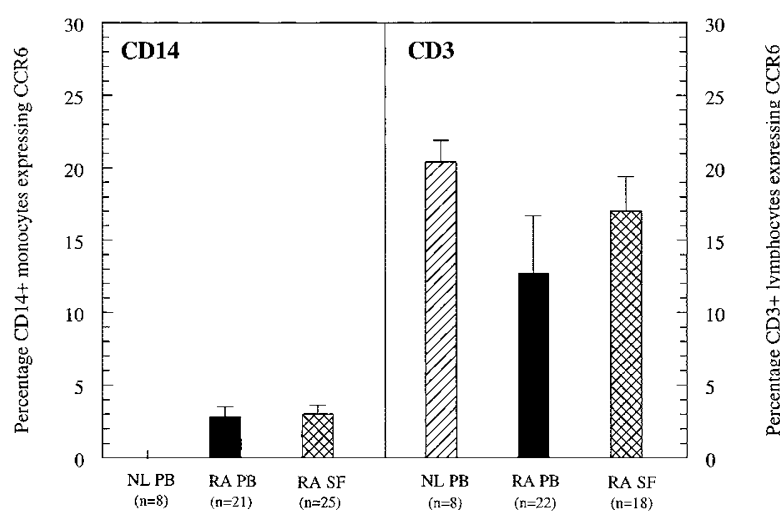

Figure 3.

Flow cytometric analysis identifying the percentage of $C D 14+$ monocytes and CD3+ lymphocytes expressing CCR6 in NL PB, RA PB, and RA SF. As shown, CD14+ monocytes did not significantly express CCR6. CD3 + lymphocytes did express CCR6, although there were no significant differences in the percentages of lymphocytes expressing CD3+/CCR6+ in NL PB, RA PB, or RA SF.

compared with CD3+/CD4+/CD45RA+/CCR6+ naive lymphocytes in both NL and RA PB (memory CD3+/CD4+/CD45RO+/CCR6 + [NL PB 19.7 \pm 2.5 , $n=3$; RA PB $33.7 \pm 3.4, n=5, p<0.05]$; naive $\mathrm{CD} 3+/ \mathrm{CD} 4+/ \mathrm{CD} 45 \mathrm{RA}+/ \mathrm{CCR} 6+[\mathrm{NL}$ PB $1.7 \pm 1.5, n$ $=4$; RA PB $2.6 \pm 0.8, n=6, p<0.05]$ ).

We also obtained clinical parameters on patients with RA. Specifically, expression of CCR6 on RA SF CD3+ lymphocytes inversely correlated with the age of the patient $(r=-0.90, p<0.05, n=6)$.

\section{TaqMan Analysis of CCR6 and MIP-3 $\alpha$ mRNA Expression in NLST, OA ST, and RA ST}

To confirm further the possibility that MIP-3 $\alpha$ and CCR6 are associated with RA, we assessed the regulation and expression of MIP-3 $\alpha$ and CCR6 in dis- eased, compared with NL tissue at the level of transcription. To do this, we measured CCR6 and MIP-3 $\alpha$ mRNA transcripts in NL, OA, and RA ST by TaqMan analysis. Results for MIP-3 $\alpha$ and CCR6 mRNA expression were normalized to GAPDH mRNA (housekeeping gene) and were expressed as mean \pm SE. As shown in Figure 5, we found approximately a 1000fold increase of CCR6 compared with MIP-3 $\alpha$ expression in OA and RA compared with NL ST by TaqMan (note scales). We also found significantly more MIP-3 $\alpha$ mRNA expression in RA ST $\left(3.3 \times 10^{-4} \pm 0.3 \times 10^{-4}\right.$, $n=3$, mean \pm SE, $p<0.05)$ and OA ST $\left(3.3 \times 10^{-4} \pm\right.$ $\left.0.3 \times 10^{-4}, n=3, p<0.05\right)$ compared with NL ST (2.1 $\left.\times 10^{-4} \pm 0.2 \times 10^{-4}, n=3\right)$. Furthermore, CCR6 was significantly higher in RA ST $(2.7 \pm 0.2, n=3, p<$ $0.05)$ and OA ST $(1.7 \pm 0.2, n=3, p<0.05)$ compared with NL ST $(0.4 \pm 0.3, n=3)$, and CCR6 mRNA expression was further up-regulated in RA ST compared with OA ST $(p<0.05)$, indicating that expression of both MIP-3 $\alpha$ and CCR6 mRNA is increased in RA ST (Fig. 5).

\section{MIP-3a is Chemotactic for Monocytes}

To determine a functional role for MIP-3 $\alpha$ in the RA joint, we determined whether MIP-3 $\alpha$ may be chemotactic for monocytes. We isolated monocytes from peripheral blood of normal volunteers and assayed monocyte chemotactic activity using a modified Boyden chemotaxis chamber. Results are shown in Figure 6 . Using graded concentrations of MIP-3 $\alpha$, we observed an increase in monocyte chemotactic activity (number of monocytes migrated in a $40 \times$ field) for MIP-3 $\alpha$ at 1.250 pM (162.6 $\pm 28.0, n=5)$, compared with HBSS control $(52.5 \pm 5.5, n=5, p<0.05)$. These results indicate that MIP- $\alpha$ is chemotactic for monocytes in vitro, suggesting that monocytes expressing CCR6 or an as-yet-unidentified receptor that can bind MIP- $3 \alpha$ are important for monocyte migration into the RA joint.

\section{MIP-3a Significantly Contributes to RA SF-Induced Monocyte Chemotaxis}

For further assessing the contribution of MIP- $3 \alpha$ to RA SF-derived monocyte chemotactic activity, RA SFderived MIP- $3 \alpha$ induction of monocyte chemotaxis was examined by immunodepletion of RA SFs with monoclonal anti-MIP-3 $\alpha$ antibody. Figure 7 shows that RA SFs depleted of MIP- $3 \alpha$ have impaired monocyte chemotaxis (overall $40 \%$ inhibition) compared with sham-depleted (nonspecific IgG) RA SFs (HBSS control, $31.0+6.0$; sample 1, IgG $112 \pm 8.0$, a-MIP-3 $\alpha 54.4 \pm 4.7, p<0.05$; sample 2, IgG $59.4 \pm$ 3.4, a-MIP-3 $\alpha 45.3 \pm 4.6, p<0.05$; sample 3, IgG $42.3 \pm 4.0$, a-MIP-3 $\alpha 29.2 \pm 2.8$, mean \pm SE cells/hpf, $p<0.05)$.

As the percentage of RA SF monocytes expressing CCR6 was low, we assessed whether another monocyte $\mathrm{G}$ protein-coupled receptor may be functioning as a receptor for $\mathrm{MIP}-3 \alpha$ and inducing monocyte chemotaxis. We incubated freshly isolated monocytes 


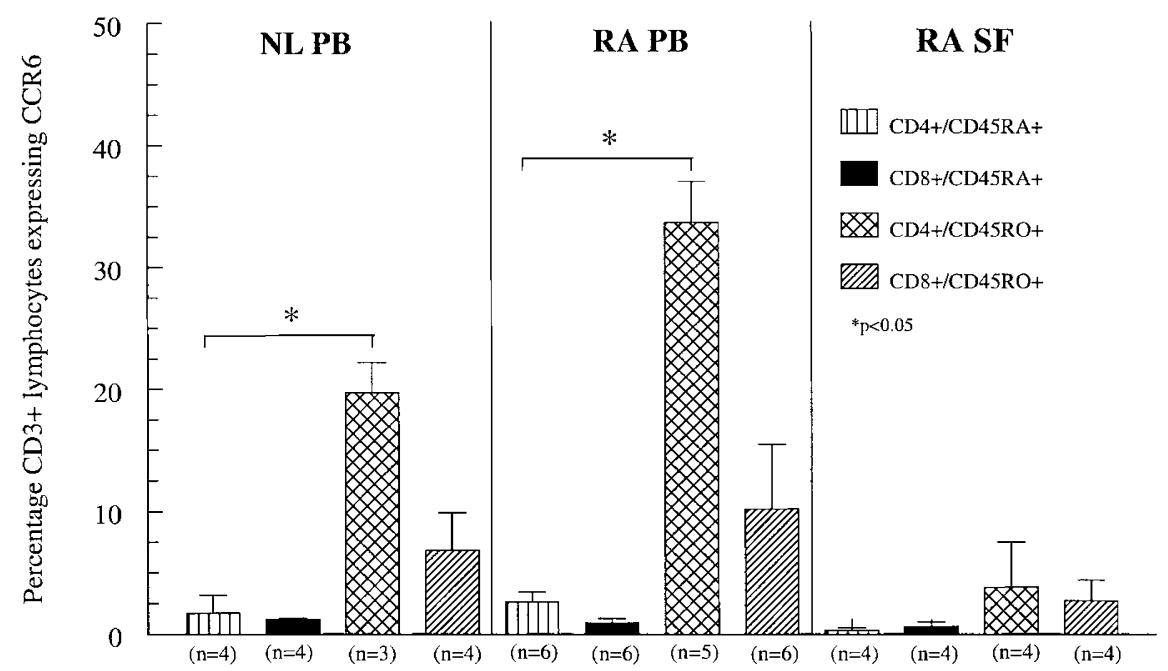

Figure 4.

Four-color FACS analysis identified percentages of $\mathrm{CD} 3+/ \mathrm{CD} 4+/ \mathrm{CD} 45 \mathrm{RA}+/ \mathrm{CCR} 6+, \mathrm{CD} 3+/ \mathrm{CD} 4+/ \mathrm{CD} 45 \mathrm{R} 0+/ \mathrm{CCR} 6+$, CD3 $+/ \mathrm{CD} 8+/ \mathrm{CD} 45 \mathrm{RA}+/ \mathrm{CCR} 6+$, and CD3+/CD8+/CD45R0+/CCR6+ expressing lymphocytes in NL PB, RA PB, and RA SF. As shown, significantly greater percentages of memory CD3+/CD4+/ CD45R0+/CCR6 + lymphocytes were found in NL and RA PB compared with percentages of naive CD3+/CD4+/CD45RA+/CCR6 + lymphocytes, indicating memory, compared with naive CD3+/CD4+/CCR6 + lymphocytes are up-regulated in NL and RA PB. The remaining lymphocyte groups did not significantly express CCR6 in NL PB, RA PB, or RA SF. Also of note is that the percentages of $C D 3+/ C D 4+/ C D 45 R 0+/ C C R 6$ + expressing memory lymphocytes were significantly elevated in RA PB compared with NL PB or RA SF, indicating that patients with RA have elevated percentages of memory CD3+/CD4+/CD45R0+ lymphocytes in RA PB.

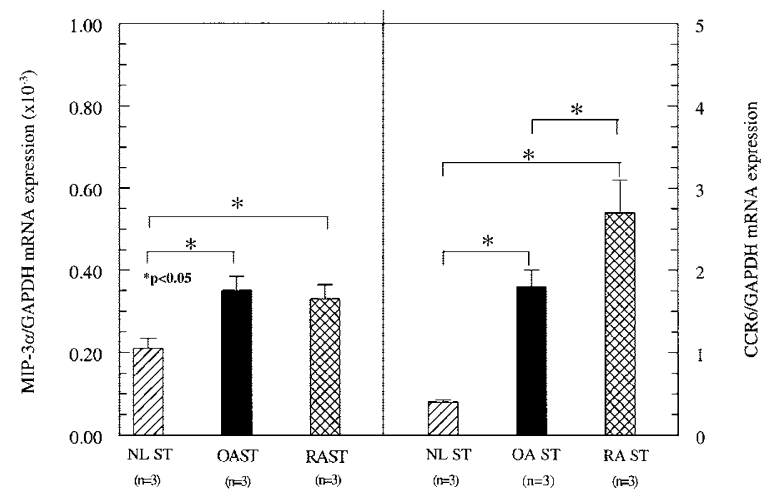

Figure 5.

MIP-3 $\alpha$ and CCR6 mRNA levels were measured by TaqMan in NL ST, RA ST, and OA ST. As shown, significantly greater amounts of MIP-3 $\alpha$ mRNA was expressed in RA and OA ST compared with NL ST $(p<0.05)$. Correspondingly, significantly enhanced concentrations of CCR6 mRNA were found in RA and OA ST compared with NL ST $(p<0.05)$, and significantly more CCR6 mRNA was found in RA ST compared with OA ST $(p<0.05)$.

with either HBSS or $1 \mu \mathrm{g} / \mathrm{ml}$ PTX. To assess monocyte chemotaxis, we used $1.250 \mathrm{pm}(10 \mathrm{ng} / \mathrm{ml}) \mathrm{MIP}-3 \alpha$ because we observed significantly enhanced monocyte chemotaxis at this concentration. As shown in Figure 8 , the number of monocytes migrating toward MIP-3 $\alpha$ (1.250 pM) was decreased with $1 \mu \mathrm{g} / \mathrm{ml}$ PTX (fMLP: $81.1 \pm 7.5, n=3$; HBSS: $51.1 \pm 4.7, n=3$; 1.250 рм MIP-3 $\alpha: 67.0 \pm 6.1, n=2 ; 1.250$ рм MIP-3 $\alpha$ with $1 \mu \mathrm{g} / \mathrm{ml}$ PTX: $30.0 \pm 4.6, n=2$ ). These results suggest that monocytes may migrate toward MIP- $3 \alpha$ by binding a $G$ protein-coupled receptor.

\section{Discussion}

Promising therapies for RA have centered on interrupting cytokine cascades, and there is a likelihood that blocking these cascades may lead to better treatments for RA. Indeed, recent advances in treating RA by inhibition of TNF- $\alpha$ have proved beneficial (Feldmann and Maini, 2001), and there also exists real promise for treating RA by inhibiting IL-1 $\beta$. It is interesting, however, that the benefits from anti-TNF- $\alpha$ therapy can vary substantially from patient to patient (Feldmann and Maini, 2001). Furthermore, a fundamental problem with inhibiting certain cytokines such as TNF- $\alpha$ is that TNF- $\alpha$ has been shown to support the in vivo levels of IL-1 receptor antagonist, a naturally produced antagonist of IL-1 $\beta$ (Charles et al, 1999; Ruth et al, 1996). Thus, inhibiting TNF- $\alpha$ could potentially drive the in vivo activity of IL-1 $\beta$.

Chemokines are chemotactic cytokines that recruit inflammatory cells, participate in inflammatory events including induction of angiogenesis (Koch et al, 1992; Park et al, 2001; Volin et al, 2001), drive specific immune responses (Ruth et al, 1998), and aid HIV entry into T cells (Deng et al, 1997). There is evidence from this and previous investigations that blocking chemokine expression and/or receptor function may lead to very promising therapies for RA (Katschke et al, 2001, Ruth et al, 2001a). This notion is supported by the fact that inflammatory leukocytes express chemokine receptors such as CCR6 (Ruth et al, 2001a) and likely use these receptors to traffic from the bloodstream to the RA joint.

This study identifies MIP- $3 \alpha$ and CCR6 as potential mediators of cell recruitment in the RA joint. In a murine allergic model of inflammation, Lukacs et al (2001) recently showed that antigen-challenged CCR6 gene-deficient mice exhibited reduced airway resistance, fewer eosinophils, reduced IL-5 in the lung, and reduced serum IgE levels. These findings showed CCR6 and MIP-3 $\alpha$ function to increase the severity of 


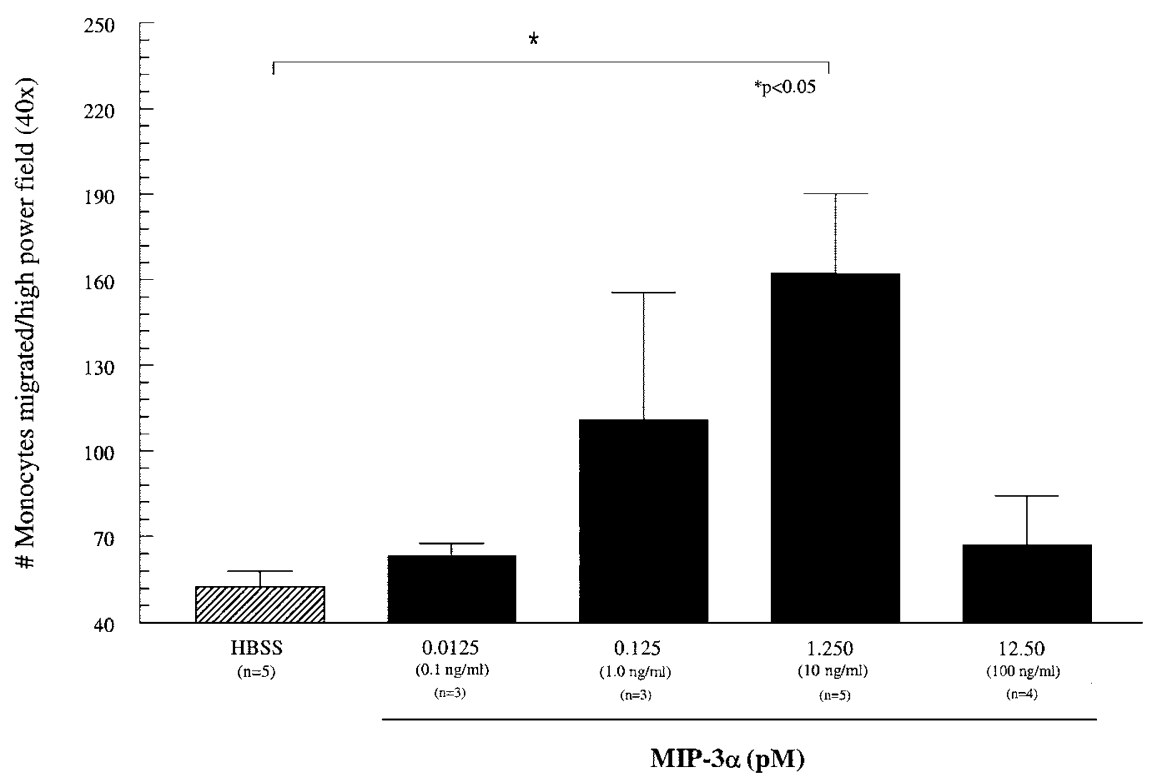

Figure 6.

MIP-3 $\alpha$ is chemotactic for monocytes. The number of monocytes migrating toward a MIP-3 $\alpha$ gradient was determined and compared with HBSS negative control MIP-3 $\alpha$ was chemotactic for monocytes compared with HBSS at $1.250 \mathrm{pm}(10 \mathrm{ng} / \mathrm{ml}) \mathrm{MIP}-3 \alpha$. Results are expressed as the mean \pm SE.

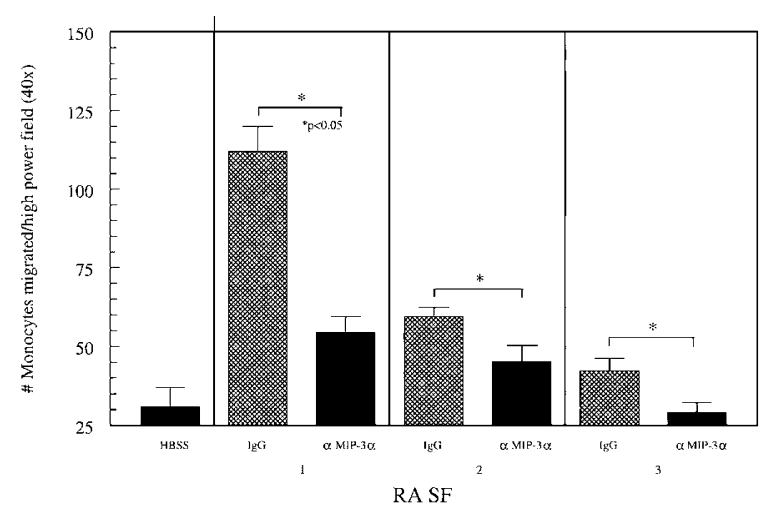

Figure 7.

MIP-3 $\alpha$ contributes to RA SF-induced monocyte chemotaxis. We immunodepleted three RA SF samples known to contain MIP-3 $\alpha$ with neutralizing anti-MIP- $3 \alpha$ antibody and inhibited monocyte chemotaxis by approximately $40 \%$ compared with sham $(\mathrm{IgG})$-treated control RA SFs. HBSS was the negative control $(30.5 \pm 6.0)$, and fMLP (not shown) was the positive control $(53.4 \pm 5.0)$. Results are expressed as the mean \pm SE.

allergic responses to antigen. CCR6 has also been implicated as a significant mediator of adoptive immunity (Yang et al, 1999). Human $\beta$-defensins, important in host defense by disrupting cytoplasmic membranes of micro-organisms, are chemotactic for immature dendritic and memory $\mathrm{T}$ cells, which are known to express CCR6. Human $\beta$-defensins were recently shown to be selectively chemotactic for cells transfected to express human CCR6, suggesting that this receptor plays a critical role in adaptive immunity (Yang et al, 1999). MIP-3 $\alpha$ has also been associated with psoriasis (Homey et al, 2000), cancer (Kleeff et al, 1999), and experimental autoimmune encephalitis (Serafini et al, 2000), which prompted interest in further characterization of MIP-3 $\alpha$ and CCR6 in RA.

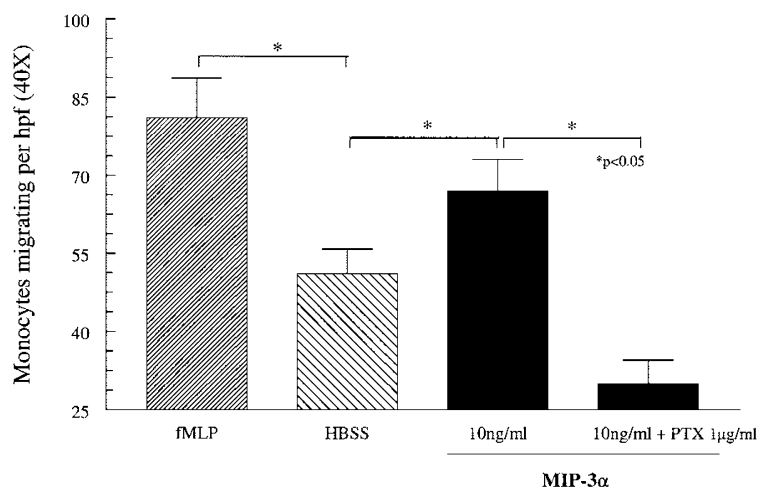

Figure 8.

FACS analysis revealed that NL PB monocytes do not express appreciable CCR6, suggesting that monocytes may be chemoattracted by MIP- $3 \alpha$ through another $\mathrm{G}$ protein-coupled receptor. To test this possibility, we incubated monocytes with the specific $G$ protein inhibitor PTX. Incubation of monocytes with $1 \mu \mathrm{g} / \mathrm{ml}$ PTX significantly inhibited monocyte migration toward $1.250 \mathrm{pm}$ $(10 \mathrm{ng} / \mathrm{ml}) \mathrm{MIP}-3 \alpha$, which was the concentration of MIP-3 $\alpha$ that induces maximal monocyte chemotaxis in vitro. Therefore, monocytes may use a $G$ protein-coupled receptor to bind and respond to MIP- $3 \alpha$ gradients. Note the lower number of monocytes migrating in response to MIP- $3 \alpha$, which may be due to the effects of incubating monocytes for 1 hour at $37^{\circ} \mathrm{C}$. Representative of two to three independent experiments.

We found significantly elevated levels of MIP-3 $\alpha$ in RA SF compared with OA SF, confirming that local and/or recruited cells contribute to MIP- $3 \alpha$ production in the RA joint. We defined the cellular source of MIP- $3 \alpha$ by culturing RA ST fibroblasts with proinflammatory cytokines and assayed supernatants for MIP$3 \alpha$. We used RA ST fibroblasts because previous investigations have shown that ST fibroblasts may secrete other chemokines into the RA SF (Ruth et al, 2001b). RA SF fibroblasts cultured with the cytokines IL-1 $\beta$, IL-18, or TNF- $\alpha$ produced MIP- $3 \alpha$, in complete 
agreement with previous investigations showing elevated levels of IL-1 $\beta$ (Szekanecz et al, 1998a), IL-18 (Gracie et al, 1999), and TNF- $\alpha$ in RA SF (Szekanecz et al, 1998a). These results extend the recent findings of Matsui et al (2001), showing that RA fibroblasts produce MIP- $3 \alpha$ in vitro in response to IL-1 $\beta$ and TNF- $\alpha$ stimulation. It is interesting that Scapini et al (2001) recently showed that neutrophils express MIP- $3 \alpha$ when stimulated with TNF- $\alpha$ in vitro. Thus, it is possible that a major source of RA SF MIP- $3 \alpha$ may be from SF neutrophils, recruited as a result of TNF- $\alpha$-stimulated RA ST fibroblast production of IL-8 and subsequent neutrophil entry into the joint (Koch et al, 1991). Therefore, RA ST fibroblasts may be induced by locally produced monokines to secrete MIP-3 $\alpha$ directly into RA SF or to produce chemokines that recruit MIP-3 $\alpha$-producing leukocytes.

By FACS analysis, we showed approximately $20 \%$ of CD3+ lymphocytes expressing CCR6 in NL PB, RA $P B$, and RA SF but did not identify differences in percentages of CD3+/CCR6+ lymphocytes between groups (all approximately 20\%). We further examined lymphocyte subset CCR6 expression using four-color FACS analysis in NL PB, RA PB, and RA SF. We identified a substantial population of $\mathrm{CD} 3+/ \mathrm{CD} 4+/$ $\mathrm{CD} 45 \mathrm{RO}+/ \mathrm{CCR} 6+$ memory lymphocytes in $\mathrm{NL}$ and RA PB but not in RA SF, indicating that CD3+/CD4+/ $\mathrm{CD} 45 \mathrm{RO}+$ memory lymphocytes either shed or internalize the CCR6 receptor upon entering the RA joint. This phenomenon is akin to that found with the fractalkine receptor $\left(\mathrm{CX}_{3} \mathrm{CR} 1\right)$, where elevated percentages of naive CD3+/CD8+ lymphocytes expressing $\mathrm{CX}_{3} \mathrm{CR} 1$ are found in RA PB but down-regulated on memory CD3+/CD8+ lymphocytes in RA PB and SF (Ruth et al, 2001a). It should be mentioned, however, that CCR6 and $\mathrm{CX}_{3} \mathrm{CR} 1$ differ in that CCR6 is not simply shed or down-regulated on lymphocytes as a result of cell activation, because memory lymphocytes also express CCR6.

The patient data showed an inverse correlation of RA SF CD3+/CCR6 lymphocyte expression and age of the patient with $R A$, indicating that older patients have less RA SF CD3+/CCR6+ expressing lymphocytes than younger patients. It is interesting to speculate that in older patients, the environment of the RA joint is such that it cannot support lymphocyte CCR6 expression or that in younger patients with, a more vigorous recruitment of CCR6-expressing lymphocytes is achieved. TaqMan mRNA analysis showed only a paucity of MIP-3 $\alpha$ compared with CCR6 message in RA ST. There was approximately a 1000-fold decrease in MIP-3 $\alpha$ mRNA compared with CCR6. However, we also found significantly higher levels of MIP-3 $\alpha$ mRNA in OA and RA compared with NL ST, indicating that MIP-3 $\alpha$ mRNA is elevated during inflammation (Matsui et al, 2001). Likewise, we found elevated CCR6 mRNA levels in OA and RA compared with NL ST and elevated CCR6 mRNA in RA compared with OA ST. This latter finding is conceivably a result of memory lymphocyte ingress into RA tissue. This is plausible because we identified approximately $20 \%$ of CD $3+$ cells expressing CCR6 in RA SF. Once in the joint, lymphocytes may further migrate to RA SF, in part as a result of high concentrations of MIP-3 $\alpha$ in RA SF as a result of fibroblast MIP- $3 \alpha$ secretion. Therefore, we propose that the increase in MIP- $3 \alpha$ mRNA in RA ST is primarily due to overproduction of TNF- $\alpha$, IL-18, and IL-1 $\beta$ from local RA ST macrophages and perhaps recruited monocytes.

Of particular interest are the significantly elevated percentages of CD3+/CD4+/CD45RO+/CCR6+ memory lymphocytes in RA PB. Thus, CCR6 mRNA found in RA ST may be primarily from recruited CD3+/CD4+/CD45RO+/CCR6+ memory lymphocytes from the RA PB. By FACS analysis, we failed to find any significant CCR6 expression on CD14+ monocytes in NL PB, RA PB, and RA SF. This is consistent with other findings that human monocytes do not express CCR6 (Baba et al, 1997) and that immature dendritic cells express CD14 at very low levels (Thomas et al, 1994). Therefore, the low level of CD14+/CCR6 + cells in the RA SF may actually be immature dendritic cell expression, as our FACS analysis cannot distinguish between these possibilities.

Because of the importance of chemokines in monocyte migration (Ruth et al, 2001b), we investigated the possibility that monocytes migrate toward MIP-3 $\alpha$ in vitro independent of CCR6. We found that monocytes migrated toward MIP-3 $\alpha$ in a dose-dependent manner, and by blocking MIP-3 $\alpha$ in RA SF with neutralizing antibody, we significantly inhibited monocyte chemotaxis by $40 \%$ compared with sham-depleted RA SFs. These experiments demonstrated that RA SF-derived MIP-3 $\alpha$ specifically induces monocyte migration in vitro. This result was surprising given that CCR6 is currently the only known receptor for MIP-3 $\alpha$ (Baba et al, 1997) but is not significantly expressed on CD14+ monocytes. Although circumstantial, this strongly suggests that monocytes use a currently unknown receptor to migrate toward MIP- $3 \alpha$ gradients. We incubated monocytes with PTX to determine whether monocytes bind MIP-3 $\alpha$ via a G protein-coupled receptor. We found that preincubating monocytes with PTX decreased monocyte chemotaxis toward optimal concentrations MIP- $3 \alpha$ by approximately $50 \%$. We also noted a decrease in monocyte migration in the PTX-treated group compared with basal levels of monocyte migration (HBSS).

In conclusion, this is the first study showing MIP- $3 \alpha$ to be chemotactic for monocytes and provides evidence that monocytes migrate in response to MIP-3 $\alpha$. By depleting RA SF of MIP- $3 \alpha$, we inhibited RA SF-induced monocyte chemotaxis by approximately $40 \%$. We also found that RA SF contains elevated concentrations of MIP- $3 \alpha$ compared with OA SF. This is due at least in part to RA ST fibroblast production as a result of IL-1 $\beta$, IL-18, and TNF- $\alpha$ stimulation (Gracie et al, 1999; Szekanecz et al, 1998a). The highest percentages of CCR6+ leukocytes were RA PB $\mathrm{CD} 3+/ \mathrm{CD} 4+/ \mathrm{CD} 45 \mathrm{RO}+$ memory lymphocytes, indicating that this memory lymphocyte subset may use CCR6 to traffic from the RA PB to the RA joint. By TaqMan analysis, we showed increased CCR6 mRNA transcripts in RA ST compared with OA and NL ST, 
likely from recruited CCR6 memory CD3+/CD4+ lymphocytes from the RA PB. Correlative RA patient data show that CD3+ lymphocyte/CCR6 expression inversely correlates with the age of the patient with RA. Overall, our data suggest that MIP-3 $\alpha$ and CCR6 function to recruit monocytes and memory lymphocytes to the RA joint and may potentially be considered appropriate targets for developing therapeutics for the treatment of RA.

\section{Materials and Methods}

\section{Patient Samples}

SF samples were obtained during arthrocentesis from patients with RA or OA. PB sera were also collected from healthy normal volunteers or from patients with RA. STs from patients with RA or OA were obtained from patients who underwent total joint replacement and met the American College of Rheumatology criteria for RA or OA. Normal STs were obtained from fresh autopsies or from amputations. All specimens were obtained with Institutional Review Board approval. Data recorded for patients with RA included age at the time of diagnosis of RA, duration of RA, erythrocyte sedimentation rate, early morning stiffness of the joints, and swollen joint count.

\section{Depletion of Rheumatoid Factor in Sera and SF}

For avoiding any possible confounding effects by rheumatoid factor (RF) on assays, RF was immunodepleted from sera and SFs using anti-IgM antibodies coupled to agarose beads (Sigma Chemical Company, St. Louis, Missouri). One half milliliter of bead slurry was washed three times with PBS (the fluid layer being aspirated off), and dry beads were mixed with $1.0 \mathrm{ml}$ of SF or sera (diluted 1:2 in PBS) and incubated overnight at $4^{\circ} \mathrm{C}$ with constant shaking. Samples were spun down (2000 rpm for 2 minutes) and collected at a final dilution of 1:2. Removal of RF (IgM) was determined by randomly choosing five RA SF samples and measuring RF levels before and after immunodepletion (RF ELISA kit; RDI, Flanders, New Jersey). Before immunodepletion, RF levels ranged from 5 to $300 \mathrm{lU} / \mathrm{ml}$. After immunodepletion, all samples had RF levels below the detection limit of the assay $(0.031 \mathrm{IU} / \mathrm{ml}$, data not shown). Samples immunodepleted of RF were used in the ELISA and chemotaxis studies.

\section{Measurement of MIP-3a}

Unless otherwise indicated, reagents were obtained from R\&D Systems (Minneapolis, Minnesota). Human MIP-3 $\alpha$ was measured in SF and sera by ELISA using 96-well polystyrene plates coated overnight at $4^{\circ} \mathrm{C}$ with $4 \mathrm{mg} / \mathrm{ml}(0.05 \mathrm{ml} /$ well) purified anti-human MIP-3 $\alpha$ IgG. After a wash of the plates with washing buffer (0.05\% PBS-Tween), plates were blocked for 2 hours at room temperature with $0.2 \mathrm{ml} /$ well $1 \%$ $\mathrm{BSA} / 5 \%$ sucrose dissolved in PBS. Recombinant human MIP- $3 \alpha$ or test supernatants were added in triplicate at a volume of $0.05 \mathrm{ml} /$ well, and plates were again incubated at $4^{\circ} \mathrm{C}$ overnight. Plates were washed three times, biotinylated anti-human MIP-3 $\alpha$ antibody (diluted 1:25 in 10\% fetal bovine serum [FBS]/PBS) was added to a final volume of 0.05 $\mathrm{ml} /$ well, and plates were incubated for 45 minutes at room temperature. Plates were washed three times, and streptavidin-peroxidase (PharMingen, San Diego, California) diluted $1: 10,000$ in 10\% FBS/PBS was added at $0.1 \mathrm{ml} /$ well, then incubated at room temperature for 1 hour. After a final wash $(\times 3)$, samples were developed with $0.2 \mathrm{ml} /$ well tetramethylbenzidine substrate (Sigma Chemical Company) diluted in a citrate/ phosphate buffer. Reactions were stopped by adding $50 \mu \mathrm{l} /$ well $2 \mathrm{M} \mathrm{H}_{2} \mathrm{SO}_{4}$, and absorbency was measured using an ELISA reader. Assay sensitivity was routinely better than $500 \mathrm{pg} / \mathrm{ml}$.

\section{RA ST Fibroblast Isolation and Culture}

ST fibroblasts isolated from patients with RA were cultured in 24-well plates (Becton Dickinson, Franklin Lakes, New Jersey) at 100,000 cells/ml for 48 hours at $37^{\circ} \mathrm{C}$ in a $5 \% \mathrm{CO}_{2}$ atmosphere. RA ST fibroblasts were grown in RPMI medium (Gibco Life Technologies) supplemented with $10 \%$ FBS/1\% penicillin/ streptomycin. For some cultures, fibroblasts were grown in media containing TNF- $\alpha$ (Pharmacia Upjohn, Kalamazoo, Michigan; $30 \mathrm{ng} / \mathrm{ml}$ ), IL-1 $\beta$ (Pharmacia Upjohn; $30 \mathrm{ng} / \mathrm{ml}$ ), or IL-18 (Pharmacia Upjohn; 30 $\mathrm{ng} / \mathrm{ml})$. Supernatants were collected after 48 hours and assayed for MIP-3 $\alpha$.

\section{Flow Cytometry}

Leukocytes were harvested from RA SFs by passage through a 40-mm mesh nylon filter to remove cellular debris. SF samples were centrifuged to pellet cells and washed twice with FACS buffer (PBS + 1\% FBS). Cells were counted and resuspended at $1 \times 10^{7}$ cells $/ \mathrm{ml}$ in blocking buffer (1\% BSA, $30 \%$ goat serum, and $0.1 \% \mathrm{NaN}_{3}$ in PBS) for 15 minutes at $4^{\circ} \mathrm{C}$. One million SF cells in $100 \mathrm{ml}$ of FACS buffer (or $100 \mathrm{ml}$ of whole blood for PB samples) were incubated with primary antibodies or nonspecific mouse IgG (Sigma Chemical Company) at a final concentration of 10 $\mathrm{mg} / \mathrm{ml}$ for 30 minutes at $4^{\circ} \mathrm{C}$.

For CCR6 studies, leukocytes were incubated with either monoclonal mouse anti-human CCR6 IgG (Millennium Pharmaceuticals, Cambridge, Massachusetts) or nonspecific mouse IgG (Sigma Chemical Company) then washed with FACS buffer and incubated with diluted (1:100 in block) goat anti-mouse or IgG Phycoerythrin (PE) antibody (Jackson Immunoresearch Laboratory, West Grove, Pennsylvania) for 30 minutes at $4^{\circ} \mathrm{C}$. Cells were washed once more with FACS buffer and incubated with mouse serum for an additional 10 minutes at room temperature. FITCconjugated anti-CD3 (detects lymphocytes) or CD14 (detects monocytes; PharMingen) was added to the cells, and the cells were incubated for 30 minutes at $4^{\circ} \mathrm{C}$. 
For some studies, CCR6 receptor expression on lymphocyte subsets was evaluated by incubating cells with anti-CD4-phycoerythrin-Texas Red-x (ECD) or anti-CD8-ECD labeled antibodies (Beckman-Coulter, Miami, Florida), added along with FITC (anti-CD45RA or anti-CD45RO) and cychrome-labeled (anti-CD3; PharMingen) antibodies, using additional histograms to evaluate memory or naive CD3+/CD4+ and CD3+/ CD8+ positive lymphocytes. Two milliliters of $1 \times$ Becton Dickinson (Bedford, Massachusetts) lysing reagent was added to the whole blood samples and incubated in the dark at room temperature for 10 minutes to allow for RBC lysis. Samples were washed twice with FACS buffer, fixed with $500 \mathrm{ml}$ of $1 \%$ formaldehyde (in PBS), then assayed in a Coulter EPICS XL-MCL (Beckman Coulter Inc., Fullerton, California). The number of events counted on the flow cytometer were routinely between 75,000 and 200,000 events/tube, depending on the experiment, with approximately $1 \times 10^{6}$ cells/tube for all experiments. Percentages of cells expressing CCR6 were calculated after defining a background value for the isotype-matched control antibody. Therefore, results were expressed as the percentage of cells staining with the control antibody background subtracted.

\section{mRNA Isolation from Human RA ST}

Human RA, OA, or NL ST were snap-frozen in liquid $\mathrm{N}_{2}$, and total cellular RNA was extracted using the Ultraspec RNA isolation system (Biotecx Laboratories, Inc., Houston, Texas). Frozen tissue (approximately 10 $\mathrm{mg}$ ) was homogenized in $0.5 \mathrm{ml}$ of homogenization buffer (Ultraspec RNA buffer), and total RNA was extracted using $1 \mathrm{vol}$ of homogenate added to $0.2 \mathrm{vol}$ of chloroform. After centrifugation $\left(12,000 \times g\right.$ at $4^{\circ} \mathrm{C}$ for 15 minutes), RNA was precipitated from the aqueous phase by adding $1 \mathrm{vol}$ of sample to an equal volume of isopropanol. Finally, RNA was washed twice in ice-cold $75 \%$ ethanol. The RNA pellet was dissolved in diethylpyrocarbonate (DEPC) water, and RNA concentrations were determined spectrophotometrically before storage at $-80^{\circ} \mathrm{C}$. Yields were routinely $>300 \mathrm{mg}$.

\section{Reverse Transcription and Taqman Quantitative PCR Analysis of Human MIP-3 $\alpha$ and CCR6 mRNA Expression from $N L, O A$, and RA ST}

All reagents were from Life Technologies unless otherwise noted. Isolated RNA was first reversedtranscribed to cDNA as follows: RNA (5 mg) was added to $1 \mathrm{ml}$ of random primer (from a stock of 50 $\mathrm{ng} / \mathrm{ml}$ ) and brought up to a total of $10 \mathrm{ml}$ with DEPC water. Samples were heated to $65^{\circ} \mathrm{C}$ for 5 minutes to denature the primer and RNA. After heating, $10 \mathrm{ml}$ of master mix was added to the RNA primer mix. The master mix consisted of $4 \mathrm{ml}$ of $5 \times$ cDNA synthesis buffer, $0.1 \mathrm{M}$ DTT, $1 \mathrm{ml}$ of RNASEOUT (40 U/ml), $1 \mathrm{ml}$ of DEPC water, and $1 \mathrm{ml}$ of Thermoscript RT (15 units $/ \mathrm{ml})$. Samples were transferred to a thermocycler and incubated at $60^{\circ} \mathrm{C}$ for 60 minutes, with the reaction terminated by incubating samples at $85^{\circ} \mathrm{C}$ for 5 minutes. cDNA was subjected to PCR in a $50-\mathrm{ml}$ total reaction volume. Briefly, $2 \mathrm{ml}$ of cDNA was added to $5 \mathrm{ml}$ of $10 \times$ high-fidelity PCR buffer, $2 \mathrm{ml}$ of $50 \mathrm{~mm}$ $\mathrm{MgSO}_{4}, 1 \mathrm{ml}$ of $10 \mathrm{~mm}$ dNTP mix, $1 \mathrm{ml}$ of $10 \mathrm{~mm}$ sense primer, $1 \mathrm{ml}$ of $10 \mathrm{~mm}$ antisense primer, $0.2 \mathrm{ml}$ of Platinum Taq High-Fidelity, and $39.8 \mathrm{ml}$ of DEPCtreated water in a thin-walled PCR tube. Amplification was performed in a thermocycler as follows: 2 minutes at $94^{\circ} \mathrm{C}$ followed by 40 cycles; 15 seconds at $94^{\circ} \mathrm{C}$; 15 seconds at $55^{\circ} \mathrm{C}$; and 1 minute at $68^{\circ} \mathrm{C}$. After cycling, samples were stored at $40^{\circ} \mathrm{C}$. Detection of PCR products was performed by analyzing PCR products by standard agarose gel electrophoresis to confirm that primers yielded predicted size products.

TaqMan PCR primers and flourogenic probes were designed using a Primer Express program v 1.01 (Perkin Elmer Applied Biosystem, San Francisco, California). Flourogenic probes carry a 5'-6-carboxy-fluorescein (FAM) reporter dye and a 3'-6-carboxy-tetramethylrhodamine (TAMRA) quencher dye (Mega Bases, Inc.). Glyceraldehyde-3-phosphate dehydrogenase (GAPDH) primers and probes were purchased from Perkin Elmer Applied Biosystem. Specifically, primer and probe sequences used for human MIP-3 $\alpha$ were (forward) 5'TGTCAGTGCTGCTACTCCACCT-3', (reverse) 5'CTGTGTATCCAAGACAGCAGTCAA-3, (probe) 5'TGCGGCGAATCAGAAGCAGCAA-3' and for human CCR6 were (forward) 5'-ACTTGGGAGGCTGAGGCAA3', (reverse) 5'-CACGATCTCGGCTCACTGC-3', (probe) 5'-CGCTTGAACCCAGGAGGCAGAGGT-5' and for human GAPDH (forward) 5'-GAAGGTGAAGGTCGGAGTC-3', (reverse) 5'-GAAGATGGTGATGGGATTC3', (probe) 5'-CAAGCTTCCCGTTCTCAGCC-3'.

TaqMan was used for MIP-3 $\alpha$ and CCR6 mRNA quantification from OA, RA, and NL ST. Briefly, $3 \mathrm{ml}$ of cDNA was added to $25 \mathrm{ml}$ (total volume) of reaction master mix containing final concentrations of $1 \times$ Platinum PCR buffer (Gibco/Life Technologies), 3.5 $\mathrm{mm} \mathrm{MgCl}_{2}, 200 \mathrm{~mm}$ dNTP, $500 \mathrm{~nm}$ of each primer (Mega Bases Inc., Chicago, Illinois), 200 nм FAMTAMRA probe (Mega Bases Inc.), 100 nм Blue 636 (BD 636), and 0.05 units of platinum TaqDNA polymerase (Gibco/Life Technologies). Samples were amplified in triplicate using the following thermal cycling conditions: $94^{\circ} \mathrm{C}$ for 5 minutes, followed by 40 cycles of amplification at $94^{\circ} \mathrm{C}$ for 30 seconds, and finally $60^{\circ} \mathrm{C}$ for 1 minute to allow for denaturing and annealingextension. cDNA quantification was directly related to fluorescence of FAM after 40 cycles of amplification. Amounts of cDNA were calculated using a standard curve (Favy et al, 2000). Estimation of amplified gene products were normalized to GAPDH (housekeeping gene), compensating for variations in quantity as well as for differences in RT efficiency.

\section{Isolation of Human Monocytes and Chemotaxis}

PB was collected in heparinized tubes from normal adult donors. After centrifugation, the buffy coat was collected and mononuclear cells were purified under sterile conditions on an Accu-Prep gradient at $400 \times g$ 
for 30 minutes at room temperature. Mononuclear cells collected at the interface were washed twice with PBS and resuspended in HBSS with calcium and magnesium (Life Technologies, Bethesda, Maryland) at $2.5 \times 10^{6} \mathrm{cells} / \mathrm{ml}$. Mononuclear cell viability was routinely greater than $98 \%$ (purity $>99 \%$ ) as determined by trypan blue exclusion. Monocyte separation was done as described previously (Ruth et al, 2001b). Briefly, $4 \mathrm{ml}$ of mononuclear cells was mixed with $8 \mathrm{ml}$ of isolation buffer $(1.65 \mathrm{ml} 10 \times$ HBSS in $10 \mathrm{ml}$ of Percoll, pH 7.0) in a 15-ml siliconized tube. After centrifugation $(400 \times g$ for 25 minutes at room temperature), monocytes were collected from the top layer of solution $(5 \mathrm{~mm})$. Monocytes were more than 95\% pure, and viability was more than $98 \%$ by trypan blue exclusion.

Monocyte chemotaxis was performed using 48-well chemotaxis chambers (Neuroprobe, Cabinjohn, Maryland) with a 5-mm polyvinylpyrrolidone-free polycarbonate filter (Poretics Corporation, Livemore, California) as previously described (Ruth et al, 2001b). Briefly, $25 \mu \mathrm{l}$ of stimulant or buffer was added to the bottom wells of the chambers. A 5-mm membrane was placed in the assembly, and $40 \mathrm{ml}$ of monocytes at $2.5 \times 10^{6}$ cells $/ \mathrm{ml}$ were placed in the top wells. The chemotaxis chamber was incubated for 1 hour in a 5\% $\mathrm{CO}_{2}$ atmosphere at $37^{\circ} \mathrm{C}$. For RA SF neutralization studies, SFs were preincubated with either specific, neutralizing anti-human MIP- $3 \alpha$ antibody (R\&D Systems) or an equivalent amount of a corresponding IgG control antibody (Ruth et al, 2001b) for 1 hour at $37^{\circ} \mathrm{C}$. Neutralized SFs were assayed for chemotactic activity for normal PB monocytes.

For some studies, the contribution of MIP-3 $\alpha$ binding to G-coupled protein receptors for monocyte chemotaxis was assessed by incubating freshly isolated monocytes $\left(4.0 \times 10^{4}\right.$ monocytes/well) with $1 \mu \mathrm{g} / \mathrm{ml}$ PTX (Sigma Chemical Company) for 1 hour at $37^{\circ} \mathrm{C}$. Monocyte chemotaxis was then performed using $1.250 \mathrm{M}(10 \mathrm{ng} / \mathrm{ml}) \mathrm{MIP}-3 \alpha$, the concentration of MIP-3 $\alpha$ observed to induce maximal chemotaxis. After incubation, filters were removed and the membranes were fixed in methanol and stained with Diff-Quik (Baxter Diagnosis, Chicago, Illinois). Assays were performed in quadruplicate with three high-power microscope $(40 \times)$ fields counted in each replicate well. Results were expressed as number of monocytes migrated per high-power field.

\section{Statistics}

The Student's $t$ test was used to compare groups. For group comparisons of RA patient data, a Pearson's coefficient of correlation was calculated. $p<0.05$ was considered statistically significant.

\section{References}

Baba M, Imai T, Nishimura M, Kakizaki M, Takagi S, Hieshima K, Nomiyama H, and Yoshie O (1997). Identification of CCR6, the specific receptor for a novel lymphocyte-directed CC chemokine LARC. J Biol Chem 272:14893-14898.
Campbell JJ, Hedrick J, Zlotnik A, Siani MA, Thompson DA, and Butcher EC (1998). Chemokines and the arrest of lymphocytes rolling under flow conditions. Science 279:381384.

Carramolino L, Kremer L, Goya I, Varona R, Buesa JM, Gutierrez J, Zaballos A, Martinez-A C, and Marquez G (1999). Down-regulation of the beta-chemokine receptor CCR6 in dendritic cells mediated by TNF-alpha and IL-4. J Leukoc Biol 66:837-844.

Charles P, Elliott MJ, Davis D, Potter A, Kalden JR, Antoni C, Breedveld FC, Smolen JS, Eberl G, deWoody K, Feldmann M, and Maini RN (1999). Regulation of cytokines, cytokine inhibitors, and acute-phase proteins following anti-TNFalpha therapy in rheumatoid arthritis. J Immunol 163:15211528.

Deng HK, Unutmaz D, KewalRamani VN, and Littman DR (1997). Expression cloning of new receptors used by simian and human immunodeficiency viruses. Nature 388:296-300.

Dieu MC, Vanbervliet B, Vicari A, Bridon JM, Oldham E, Ait-Yahia S, Briere F, Zlotnik A, Lebecque S, and Caux C (1998). Selective recruitment of immature and mature dendritic cells by distinct chemokines expressed in different anatomic sites. J Exp Med 188:373-386.

Favy DA, Lafarge S, Rio P, Vissac C, Bignon YJ, and BernardGallon D (2000). Real-time PCR quantification of full-length and exon 11 spliced BRCA1 transcripts in human breast cancer cell lines. Biochem Biophys Res Commun 274:73-78.

Feldmann M and Maini RN (2001). Anti-TNF alpha therapy of rheumatoid arthritis: What have we learned? Annu Rev Immunol 19:163-196.

Gracie JA, Forsey RJ, Chan WL, Gilmour A, Leung BP, Greer MR, Kennedy K, Carter R, Wei XQ, Xu D, Field M, Foulis A, Liew FY, and Mclnnes IB (1999). A proinflammatory role for IL-18 in rheumatoid arthritis. J Clin Invest 104:1393-1401.

Homey B, Dieu-Nosjean MC, Wiesenborn A, Massacrier C, Pin JJ, Oldham E, Catron D, Buchanan ME, Muller A, deWaal MR, Deng G, Orozco R, Ruzicka T, Lehmann P, Lebecque S, Caux C, and Zlotnik A (2000). Up-regulation of macrophage inflammatory protein-3 alpha/CCL20 and CC chemokine receptor 6 in psoriasis. J Immunol 164:6621-6632.

Katschke KJ Jr, Rottman JB, Ruth JH, Qin S, Wu L, LaRosa G, Ponath P, Park CC, Pope RM, and Koch AE (2001). Differential expression of chemokine receptors on peripheral blood, synovial fluid, and synovial tissue monocytes/macrophages in rheumatoid arthritis. Arthritis Rheum 44:1022-1032.

Kleeff J, Kusama T, Rossi DL, Ishiwata T, Maruyama H, Friess H, Buchler MW, Zlotnik A, and Korc M (1999). Detection and localization of Mip-3alpha/LARC/Exodus, a macrophage proinflammatory chemokine, and its CCR6 receptor in human pancreatic cancer. Int J Cancer 81:650-657.

Koch AE, Kunkel SL, Burrows JC, Evanoff HL, Haines GK, Pope RM, and Strieter RM (1991). Synovial tissue macrophage as a source of the chemotactic cytokine IL-8. J Immunol 147:2187-2195.

Koch AE, Polverini PJ, Kunkel SL, Harlow LA, DiPietro LA, Elner VM, Elner SG, and Strieter RM (1992). Interleukin-8 as a macrophage-derived mediator of angiogenesis. Science 258: 1798-1801.

Liao F, Rabin RL, Smith CS, Sharma G, Nutman TB, and Farber JM (1999). CC-chemokine receptor 6 is expressed on diverse memory subsets of $T$ cells and determines respon- 
siveness to macrophage inflammatory protein 3 alpha. J Immunol 162:186-194.

Lukacs NW, Prosser DM, Wiekowski M, Lira SA, and Cook DN (2001). Requirement for the chemokine receptor CCR6 in allergic pulmonary inflammation. J Exp Med 194:551-555.

Matsui T, Akahoshi T, Namai R, Hashimoto A, Kurihara Y, Rana M, Nishimura A, Endo H, Kitasato H, Kawai S, Takagishi $\mathrm{K}$, and Kondo H (2001). Selective recruitment of CCR6expressing cells by increased production of MIP-3 alpha in rheumatoid arthritis. Clin Exp Immunol 125:155-161.

Nakayama T, Fujisawa R, Yamada H, Horikawa T, Kawasaki H, Hieshima K, Izawa D, Fujiie S, Tezuka T, and Yoshie O (2001). Inducible expression of a CC chemokine liver- and activation-regulated chemokine (LARC)/macrophage inflammatory protein (MIP)-3 alpha/CCL20 by epidermal keratinocytes and its role in atopic dermatitis. Int Immunol 13:95-103.

Park CC, Morel JC, Amin MA, Connors MA, Harlow LA, and Koch AE (2001). Evidence of IL-18 as a novel angiogenic mediator. J Immunol 167:1644-1653.

Power CA, Church DJ, Meyer A, Alouani S, Proudfoot AE, Clark-Lewis I, Sozzani S, Mantovani A, and Wells TN (1997). Cloning and characterization of a specific receptor for the novel CC chemokine MIP-3alpha from lung dendritic cells. J Exp Med 186:825-835.

Ruth JH, Bienkowski M, Warmington KS, Lincoln PM, Kunkel SL, and Chensue SW (1996). IL-1 receptor antagonist (IL-1 ra) expression, function, and cytokine-mediated regulation during mycobacterial and schistosomal antigen-elicited granuloma formation. J Immunol 156:2503-2509.

Ruth JH, Lukacs NW, Warmington KS, Polak TJ, Burdick M, Kunkel SL, Strieter RM, and Chensue SW (1998). Expression and participation of eotaxin during mycobacterial (type 1) and schistosomal (type 2) antigen-elicited granuloma formation. J Immunol 161:4276-4282.

Ruth JH, Rottman JB, Katschke KJ Jr, Qin S, Wu L, LaRosa G, Ponath P, Pope RM, and Koch AE (2001a). Selective lymphocyte chemokine receptor expression in the rheumatoid joint. Arthritis Rheum 44:2750-2760.

Ruth JH, Volin MV, Haines III GK, Woodruff DC, Katschke KJ Jr, Woods JM, Park CC, Morel JCM, and Koch AE (2001b). Fractalkine, a novel chemokine in rheumatoid arthritis and in rat adjuvant-induced arthritis. Arthritis Rheum 44:15681581.
Scapini P, Laudanna C, Pinardi C, Allavena P, Mantovani A, Sozzani S, and Cassatella MA (2001). Neutrophils produce biologically active macrophage inflammatory protein-3alpha (MIP-3alpha)/CCL20 and MIP-3beta/CCL19. Eur J Immunol 31:1981-1988.

Schutyser E, Struyf S, Menten P, Lenaerts JP, Conings R, Put W, Wuyts A, Proost P, and Van DJ (2000). Regulated production and molecular diversity of human liver and activation-regulated chemokine/macrophage inflammatory protein-3 alpha from normal and transformed cells. J Immunol 165:4470-4477.

Serafini B, Columba-Cabezas S, Di RF, and Aloisi F (2000). Intracerebral recruitment and maturation of dendritic cells in the onset and progression of experimental autoimmune encephalomyelitis. Am J Pathol 157:1991-2002.

Sullivan SK, McGrath DA, Liao F, Boehme SA, Farber JM, and Bacon KB (1999). MIP-3alpha induces human eosinophil migration and activation of the mitogen-activated protein kinases (p42/p44 MAPK). J Leukoc Biol 66:674-682.

Szekanecz Z, Koch AE, Kunkel SL, and Strieter RM (1998a). Cytokines in rheumatoid arthritis: Potential targets for pharmacological intervention. Drug Aging 12:377-390.

Szekanecz Z, Strieter RM, Kunkel SL, and Koch AE (1998b). Chemokines in rheumatoid arthritis. Springer Semin Immunopathol 20:115-132.

Thomas R, Davis LS, and Lipsky PE (1994). Rheumatoid synovium is enriched in mature antigen-presenting dendritic cells. J Immunol 152:2613-2623.

Volin MV, Woods JM, Amin MA, Connors MA, Harlow LA, and Koch AE (2001). Fractalkine: A novel angiogenic chemokine in rheumatoid arthritis. Am J Pathol 159:1521-1530.

Yang D, Chertov O, Bykovskaia SN, Chen Q, Buffo MJ, Shogan J, Anderson M, Schroder JM, Wang JM, Howard OM, and Oppenheim JJ (1999). Beta-defensins: Linking innate and adaptive immunity through dendritic and $\mathrm{T}$ cell CCR6. Science 286:525-528. 